\title{
A School Library in Sub-Saharan Africa
}

\author{
Johanna Anderson
}

\section{Abstract}

This paper reports on the success and suitability of a Western-donated school library in furthering literacy and reader development in Malawi.

A qualitative, case study approach was taken using semi-structured interviews with teachers and a library assistant at a primary school in Malawi.

The research reveals positive attitudes towards reading and literacy in a predominantly oral culture. Limitations include a lack of attention to reader development and inappropriateness of materials for the local context.

The study reveals that the book donation model commonly supported by international donors and non-governmental organisations (NGOs) falls short in its ability to contribute to global literacy and education targets. Recommendations to improve impact are given.

This research is original in representing the voices of school teachers in the debate over the suitability of libraries and the overseas book donation model to the subSaharan African context.

\section{Introduction}

Access to free, universal primary education for all is a basic human right, the attainment of which is one of the eight Millennium Development Goals (MDGs) agreed upon by the United Nations in 2000, to be met by 2015 (United Nations Development Programme, 2000).

Literacy is recognised by The United Nations Educational, Scientific and Cultural Organization (Unesco) as a fundamental human right which has a central role to play in tackling global poverty (Unesco, 2005).

For most people in sub-Saharan Africa, primary school provides the first opportunity to acquire literacy skills but pupil to teacher ratios is typically very high and if there are any books available in the school they are often just a few

\section{Author}

Johanna Anderson is an academic librarian at the University of Gloucestershire

Email: johannaanders25@hotmail.com

Received 04 March 2011

Accepted 08 May 2011 
government text books which have to be shared between six or more pupils at a time (Makotsi, 2004, 6). There are rarely the resources available to create a literate environment.

Non-governmental organisations (NGOs) and donors have traditionally attempted to address the lack of resources through the donation of surplus Western books and educational material. While much current research focuses on how information and communication technologies (ICT) can facilitate access to information in developing countries, lack of electricity, computer access and internet connection (World Economic Forum, 2009) still mean that book donation has a large role to play and libraries are ideally suited to fill the resource gap.

With sufficient investment and support, libraries will have a major positive impact on the achievement of Education for All and the Millennium Development Goals. (Krolak, 2005, 13)

Book donations come in two forms, the solicited and the unsolicited. Unsolicited book donations are the easiest to obtain, and therefore the most common. Donors who provide solicited material generally insist on proof that the resources will be used effectively before assistance is secured. This requires skill and patience from the requester because impact and effectiveness are difficult to measure and competition for the resources is great. Unsolicited donations rarely have provisos attached. There is concern that where the unsolicited book donation approach is used, professional needs assessments are seldom undertaken and continuing monitoring and evaluation procedures, with active community participation, are rarely implemented (Krolak, 2005). The result is the provision of information services that are based upon assumptions and not on actual need.

Since the 1960s there has been much scrutiny of library aid; the tone of which has changed little. However, many of the theories and conclusions presented by the literature have been arrived at via desk-based research and there is a lack of first hand data available.

This paper reports the findings of a research project that was designed, using a largely qualitative approach, to investigate library aid from the recipient's perspective so that library aid donors can be better informed about the people they are serving. The intention was to inform future practice and research.

The research questions posed in the study were:

1. Does reading have a role to play in a traditionally oral culture?

2. How relevant is donated book stock to library users?

3. How is library stock used and, in light of this, what impact does it have?

4. How is reader development supported?

\section{Methodology}

A case study research project was conducted at Cape Maclear Primary School, Chembe village, in Malawi, over a three-week period in November 2008. Semistructured interviews with the teachers and the library assistant were analysed 
alongside internal documentation collected, which included exam statistics and diary-like reports written by the library assistant since the library was installed.

The voice of library aid recipients in Sub-Saharan Africa is very poorly represented in existing literature so a largely participatory approach was considered the most appropriate method to use as this "enhanced the opportunity to reveal aspects of social worlds that are important to the participants that might not otherwise cross the mind of the unacquainted researcher" (Bryman, 2001, 280), thus allowing the researcher to establish the opinions and needs of the library aid recipients in depth.

Twelve of the thirteen teachers at the school, including the head teacher, agreed to be interviewed as did the library assistant. The questions were designed to encourage the interviewee to think in depth about many aspects of the library, such as patterns of usage, the relevance of the stock, and the role of reading in Malawian culture.

The interviews were recorded and transcribed verbatim and then analysed alongside the internal documents that had been collected, using data management and analysis software NVivo.

\section{Context for the research}

Malawi is culturally and economically representative of many sub-Saharan African countries. It is landlocked, has few natural resources, is one of the least developed countries in the world, and despite its rich cultural diversity, has an oral culture that features many similarities to other sub-Saharan African societies. Malawi used to be an English protectorate and its official language is English despite its people predominantly speaking Chichewa, their local language, as a first language.

The Malawian government abolished primary school education fees in 1994 (UNDP, 2003, 4), however there were not the materials to support the increase of student numbers that this resulted in. A small NGO based in Bristol, United Kingdom (UK) is attempting to address this need for educational material by shipping unsolicited donated English material to schools in Malawi and setting up libraries.

The NGO installed a library in rural Malawi at Cape Maclear Primary School in 2005 with the intention of setting up more in the future. Since its installation they have funded a library assistant, selected by them, to work in the library at the primary school. The library assistant received no training and has not completed secondary education himself. The teachers and library assistant at the school had no knowledge of the stock selection before it reached them.

The NGO rely on book donations from Western publishers, British schools that donate surplus or unwanted stock, and other private donations. The stock selection policy is informal and the recipient schools are left to run the library as they see fit. 


\section{The literature}

Before discussing the findings of the primary research conducted in Malawi, key ideas from the available literature are presented, which suggest that cultural traits, teaching methods and language barriers are all major obstacles that need to be tackled if the low levels of literacy in sub-Saharan Africa are to be addressed.

\subsection{Culture and literacy}

Commentators often state that sub-Saharan Africa lacks a reading culture (Totemeyer, 1994; Sturges and Neill, 1998; Rosenberg, 2003; Krolak, 2005). Totemeyer (1994, 413), suggests that this is because sub-Saharan Africa's oral culture renders reading redundant - people stop reading once they complete their schooling as they "derive more pleasure from the oral and performing arts". As most adults in sub-Saharan Africa are non-literate they do not read at home, and if reading does not take place at home then a reading culture will not develop. The non-literate majority affect the literate minority and as such oral modes of communication remain prevalent. Sturges and Neill $(1998,68)$ posit that the act of reading is not only superfluous to oral traditions but it is in discord with traditional values. In oral traditions trusted sources of information are community chiefs and not the written word in a foreign book. What is more, "both the content of the books and the solitude required to read them conflict with traditional values, making them at once less comprehensible and less acceptable" (Sturges and Neill, 1998, 150).

Similar conclusions regarding cultural preferences and traits feature throughout the discourse on libraries and literacy in sub-Saharan Africa, suggesting a limited role or cultural ceiling for reading. However, these claims are contradicted in the few qualitative studies that have been undertaken. When assessing the information needs of a rural sub Saharan African community (Sturges and Chimseu 1996) observed that print material is widely valued and that some traits of an oral culture actually facilitate access to the written word. For example it is "shared by the literate (often school children) with the non-literate". A South African initiative called "Born to Read" (Mtshweni, 2003, 9), which encouraged non-literate mothers to become library members and read with their children by using the pictures in books to tell a story, found that this was welcomed as it promoted traditional storytelling. Instead of the reading culture being stifled by an oral tradition where some may say it had no place, the mothers could identify similarities of storytelling in their own culture with the storytelling using books, thus enabling them to use their experience to introduce their children to reading in a way that they were comfortable with. By gaining an understanding of the local culture and what was important to the participants it was possible to take an approach that exploited synergies between oral and literate cultures.

\subsection{Teaching and Reader Development}

Reader development focuses on fostering a reading habit by developing positive attitudes towards reading, which in turn creates positive attitudes towards the development of reading skills. It is active intervention to sell: 
..the reading experience and what it can do for you [...] recognizing that reading has a crucial role to play in creating independent learners, underpinning literacy skills and educational attainment, and helping people understand themselves and others better. It starts with librarians introducing very young babies to books and carries on throughout the ages.

(Rosenberg, 2003, 4)

Many commentators lament the fact that teachers in sub-Saharan Africa do not have the knowledge or experience to encourage reader development so that when they are given access to books the resources are not used to their full potential. Sturges and Neill $(1998,163)$ claim that it is hard to convince teachers in subSaharan African schools the value of libraries due, not only to a previous lack of access to books, but also to the difficulty of persuading teachers to use teaching methods other than the ones with which they are familiar. Williams $(1998,14)$ observed reading classes in primary schools in Malawi and Zambia and found that the predominant method of teaching is the drilling of words and sentences through repetition. This method of teaching merely serves to reinforce structural patterns and does little to attend to meaning.

It is no guarantee of understanding and at worst is simply a performance which masks a lack of real competence.

(Williams, 1998, 14)

These teaching methods are not suitable for teaching children in a second language and they are not conducive to reader development and the raising of literacy standards.

The active support of reader development is vital to the growth of a reading culture in sub-Saharan Africa. However, "it is not yet regarded as a core aspect of service provision in libraries in developing countries" Rosenberg (2003, iv) and it is an area that is rarely discussed in the literature.

In the available literature, the voice of the teachers is distinctly lacking. As teaching methods and attitudes have a pivotal role to play in reader development and the growth of a reading culture, it was hoped that by engaging the teachers in dialogue for the research project, new ideas would emerge on how reader development can be adapted to their situation.

\subsection{Language}

In sub-Saharan Africa, Western books donated by NGOs and 80 per cent of new titles from Africa are in ex-colonial languages, particularly English and French, despite the fact that less than 5 per cent of the continent's population is regarded as being fluent in either of them (Sturges and Neill, 1998, 26). In sub-Saharan Africa, children mainly begin their preschool and early school lives communicating only in their local language. When they reach higher classes they are taught in languages such as English or French, which to them, although they are their country's official languages, are essentially foreign languages.

A study of bilingual literacy and teaching practices in Malawi and Zambia, concluded that students in Malawi do not read English well enough to be able to 
use it to learn in other subjects (Williams, 1998, 58). This is of serious concern if the only books that the children have access to are written in English.

\section{Findings}

As is evident from the literature there are many perceived barriers to the development of a reading culture in Sub-Saharan Africa. The following sections detail the findings of the research project which investigated these issues from the recipient's perspective.

\subsection{Culture and Literacy}

The research found that the community members in Cape Maclear with an interest in reading are predominantly the newly literate, such as the recent school leavers and secondary school pupils, who frequently request to use the books.

As it is often only school children who have access to the information in books and newspapers, due to a lack of external resources coupled with adult illiteracy, information no longer just flows from the elders to the children. The books provide children with access to information, which they then share with their parents. The sharing of information from books between the literate and nonliterate encourages readers and turns the typically lone activity into a social one.

The role of reading is very much seen as educational. Contrary to the claims of Sturges and Neill $(1998,150)$, the teachers say the attitudes of the community towards reading are positive. Books are associated with knowledge and wealth and to be seen with one gives prestige so some members of the community request to use the library books even if they cannot read.

Malawians cannot afford to travel to learn about other countries and cultures, books are one of the few ways they can access this knowledge. Access to knowledge about the world is considered to have the potential to change Malawians' behaviour, culture and to improve their standard of living. The teachers see Western visitors and the countries they come from as economically successful, so by imitating an economically successful culture they hope to achieve economic stability also.

At Cape Maclear Primary School, the teachers credit these positive attitudes towards reading and education in Malawian society to the stance of the current government:

In previous years the government introduced adult literacy schools so that they know reading [and] writing, but ten years ago [literacy levels] went down again, now they are coming up again. [Literacy levels decreased because] the government didn't encourage it, because ten/five years ago the government was not a party to education... was not all that interested. But as of now, with the new president, he is encouraging it now and I hope that in five, a few years coming I hope we've evolved. [Adult literacy classes are happening] again, here in Chembe village where we are.

This has had a direct impact on the community: 
Our life depends in the lake because it is where we get fish; we get money after selling the fish. Because of this our old parents didn't write, they were busy catching fish in the lake, so most of them didn't go to school. . .but now people are sending their pupils to learn here. It is also encouraging parents to send their people because they are seeing now, some children, they are working after school. ..they are getting money. . . so, when they see what is happening, they are sending their pupils here.

For those interested in the development of a reading culture in Malawi this encouragement from the parents is an exciting finding if $\operatorname{Krolak}(2005,4)$ is correct in her claim that "the desire to support the literacy acquisition of their children is a strong motivation for illiterate adults to become literate". She suggests that this should be seen as an opportunity to reach the adults through family literacy programmes especially as school children are more likely to be successful at school if they come from literate or semi-literate homes.

The findings indicate that reading does have a role to play in an oral culture; the barriers, which stand in the way of a reading culture taking root are poverty and lack of education rather than cultural influences.

\subsection{Teaching and Reader Development}

The teachers recognise that the library provides the children with the opportunity to utilise the books in a way they never could before,

Children understand by seeing, touching, feeling . . this library have really helped this school. They have really improved in their reading and learning capacity. We had not enough materials from the government so some of the children have never seen a book or taken a book to read, just, reading or hearing the teacher, so in having a library, they go in to the library, they take a book, they see the picture, they read the words ... In so doing they add more knowledge to what they have been taught in class.

The teachers have high expectations of the library's ability to facilitate independent learning and hope that the children will obtain knowledge that they cannot access in class due to the large student numbers and a lack of individual attention from the teachers. However, the language barriers that the children face render the books inaccessible so, in practice, the teachers have to act as intermediaries. Most of the teachers do not take the library books into the classroom but they get information from the books, which they then add to their lessons.

In this school, the children are only allowed access to the books from standard 5 onwards; the age of standard 4 students can range from nine to sixteen so it is possible that a child can be as old as sixteen before having any access to the books, and at least as old as nine. As the books are written in English and the children do not begin to get taught in English until these later grades it is seen as pointless to be giving them access to books they cannot understand. However, it is not just the younger children who have problems with language barriers; the older children face difficulties also: 
Even these guys who are in the elder class not most of them they can understand English very well. Not most of them they can understand these bombastic words that are found in the books so they always come and ask me, "Please interpret this for us". (Library assistant)

Four of the teachers "sometimes" take the children to the library during the school day but because the classes are so big and the library so small they have to take it in turns. This is both impractical and time consuming. The class sizes often reach 100 but there is only room for ten pupils at a time in the library.

This study indicates that Sturges and Neill's $(1998,163)$ suggestion that teachers in Africa are hard to convince of the value of libraries is incorrect. All of the teachers interviewed see the value of the library and think it is important to encourage the older children to go to the library if they have problems with their studies, to practice reading, and to expand their knowledge. Indeed, they almost see it as a substitute teacher. This approach is dependent on the child's initiative to act on this advice and on the library assistant's support once they are in the library. The children do not have access to books in the classroom, they are not given consistent, regular library time during the school day and there was little evidence to indicate that children are actively being taught independent research skills yet they are still expected to be independent learners.

The library assistant notices that the children are good at memorising information read to them from books but observes that when asked to explain what they have read, using their first language Chichewa, they are unable to do so. This corroborates Williams (1998) findings that the teaching methods used in the classroom focus on learning by rote but neglect to establish and ensure understanding.

Despite receiving no training and having not completed secondary school himself, the library assistant does much of the reading, library and book promotion work. He talks to students during assemblies and gatherings, explaining how using the books can help them in their exams and later in life. He helps the students to understand the books by explaining the meanings of words and "topics they do not understand".

Only two of the teachers read for pleasure; in contrast, the library assistant frequently mentioned leisure and the fun aspects of the library in his reports and interview, expressing a different attitude towards reading:

Children come to the library because of the funny games and pictures, as you know kids are very much attracted to the pictures and they learn through that they always have great fun.

Although many of the teachers use the library for personal reading the reasons given for this always relate to how the information within these books supports their jobs. This is an important role for the library as it is the teachers' only access to books.

If I stay away from that then I will never impart knowledge to the children, because our careers as teachers, as a teacher I have to be reading continuously. 
So the library is now an important part of our being encouraged in our learning as well as teaching.

It is clear from the findings that the provision of donated book stock alone will not overcome the barriers to literacy and reader development. Professional support and training is required as well as the adaptation of teaching styles and use of resources.

\section{Implications}

As is evident in this case study, thorough consultation with library aid recipients can reveal important aspects that the external donor may not have otherwise considered, aspects that will be crucial in informing the direction that a library project should take and how a service can be made relevant and effective. Library aid donors must not make assumptions about the community they wish to assist if inaccurate presumptions that undermine the aims of a project are to be avoided. Project evaluation using both qualitative and quantitative data is still lacking in the area of library aid, this study suggests that this must be addressed.

Experience from the case study suggests that donors, working alongside governments, must work with information professionals and education experts to develop innovative reader development programmes that utilize the traits of the community to engage everyone in reading. For example, in this study it was revealed that:

- New literates were a theme throughout the findings. New literates can slip back into illiteracy if they do not have access to reading materials post-school. This section of the community should not be overlooked by library providers. Reader development should be a lifelong, continuous process. The evident interest in learning about the outside world shown in this study and the desire for continued education is an ideal basis on which to encourage people to read.

- Information from books gets shared orally from the literate to the non-literate. The sharing of stories and the experience of reading is a prime factor of reader development. How can this highly sociable trait of an oral culture be used to engage more people in reading and facilitate involvement of non-literate community members? The new enthusiasm from parents due to government influence could be harnessed to help develop a reading culture but it would need community participation and relevant resources.

- Education and knowledge are associated with wealth. To be seen with a book gives one prestige. How can this be transformed into increased literacy levels and active engagement with library resources?

- The teachers and library assistant place great emphasis on the value of independent study, an important aspect of reader development, yet the current situation does not enable the children to utilize the library in this way. How can the teachers and library assistant be supported in developing the children's independent study skills? Library aid projects should consider training to be as essential as the provision of relevant books; training is necessary to help the teachers and the library assistant to use the resources that are already available 
to them more effectively. Book donations and enthusiasm from the stakeholders alone is not sufficient; professional support is also vital.

\section{Future research}

Future research is also recommended in the following areas:

- The few reader development programmes that have been researched and evaluated illustrate that if managed, directed and supported appropriately cultural traits can actually facilitate access to the written word. Reader development activity in sub-Saharan Africa is a new and emerging area that requires more evaluation and research without which resources will not be used to their full potential.

- Language barriers were a constant theme in this study. It is suggested that research be carried out regarding how this can be addressed. Zeleza (2002) reports that the supremacy of the English language hinders the success of local language publishing, if this is the case perhaps donors should look towards providing material used specifically for teaching English as a foreign language rather than just providing material printed in the English language.

- In this study the teachers and library assistant spoke for the children and the community. A repeat of this study extended to collecting first-hand data from these library stakeholders is recommended to provide a more comprehensive picture.

- No librarians, teachers, education or development experts were employed by the NGO featured in this study. It is recommended that research be carried out to establish whether this is endemic and if so, why? Philanthropic endeavours can have a vital role to play in international development. However, they must be subjected to quality insurance measures and regulation if they are to be directed effectively and appropriately. The NGO central to this study was formed on good intentions and philanthropy. However, a lack of consultation with professionals and the library users, a lack of consideration of the specialist training needed for the library assistant and no evaluation of their service in the five years since its installation, has limited the library's potential to serve its purpose despite the high expectations of the teachers.

\section{Conclusion}

One of the teachers interviewed for this study said:

I think in Malawi it is the song of the government, they decide that in every part and every learning area there must be a librarian, but the libraries must grow because it is a matter of encouraging a child to read . . . now a library is most important to our lifespan of our learning, really. . . Yes this is a very serious matter.

Libraries, the library profession and the book donation model have vital contributions to make to global priorities for human development, particularly with the agreement of the Millennium Development Goals and the emphasis placed on education and literacy by African governments such as Malawi's. 
However, as librarians and libraries in the UK fight for funding and recognition it is likely that, as is evident in this case study, trained staff and professionals are overlooked in the consultation process by UK based NGOs and development agencies. Any short term financial savings made by not employing or consulting library professionals can only be a false economy if the resources that are shipped overseas at great cost are not properly planned and directed and do not fulfil their potential. If not matched to need and supported with capacity building the widely used book donation model will fall short in its ability to contribute to global literacy and education targets.

\section{References}

Bryman, A. (2001) Social Research Methods. Oxford: Oxford University Press.

Krolak, L. (2005) The role of libraries in the creation of literate environments. Hamburg: UNESCO. URL: http://www.ifla.org/VII/s33/pub/s33_Krolak\%20L.pdf [accessed 08.8.11].

Makotsi, R. (2004) Sharing resources - how library networks can help reach education goals. Research paper commissioned by Book Aid International, London. URL: http://www.bookaid.org/wp-content/uploads/2011/06/SharingResources-how-library-networks-can-help-reach-education-goals.pdf [accessed 08.8.11].

Mtshweni, D. (2003) Born to read: a programme of the Gauteng department of sport, recreation arts, culture, library and information services. In: Rosenberg, D. (ed.) Reader development and reading promotion: recent experiences from seven countries in Africa. Oxford: INASP. 1-12. URL:

http://www.inasp.info/file/cff64e599486bfe3c3c492aa973cf152/book-readerdevelopment-and-reading-promotion.html [accessed 08.8.11].

Otike, J. N. (1993) Book donations and their relevance to the Third World. New Library World. 94(1107), 10-14.

Rosenberg, D. (ed.) (2003) Reader development and reading promotion: recent experiences from seven countries in Africa. Oxford: INASP. URL: http://www.inasp.info/file/cff64e599486bfe3c3c492aa973cf152/book-readerdevelopment-and-reading-promotion.html [accessed 08.8.11].

Sturges, P., Chimseu, George. (1996) Qualitative research in information studies: a Malawian study. Education for Information, 14(2), 117-127.

Sturges, P., Neill, R. (1998) The quiet struggle: information and libraries for the people of Africa. 2nd ed. London: Mansell. URL: http://www-

staff.lboro.ac.uk/ 1srps/quiet $\% 20$ struggle\%20e-

book/the $\% 20$ quiet $\% 20$ struggle $\% 20$ small $\% 20$ version/the $\% 20$ quiet $\% 20$ struggle $\% 2$ 0pdf/the\%20quiet\%20struggle\%20electronic\%20edition\%202.pdf [accessed: 08.8.11].

Tötemeyer, A. J. (1994) Speaking from a book: the transfer of de-recorded information of the information starved. IFLA Journal. 20(4), 410-418. 
United Nations Development Programme (2003) Malawi: Millennium development goals report 2003. URL:

http://www.undp.org.mw/reports/MALAWI\%20MDGr\%202003.pdf [accessed 08 .8.11].

United Nations Development Programme (2005) Human development report 2005. UNDP, New York. URL:

http://hdr.undp.org/en/media/HDR05_frontmatter.pdf [accessed 08.8.11].

United Nations Educational, Scientific and Cultural Organisation (2004) The development of education in Malawi. 2004 report. Prepared for the $47^{\text {th }}$ Session of the International Conference on Education. UNESCO. URL:

http://www.ibe.unesco.org/International/ICE47/English/Natreps/reports/malawi.p df [accessed 08.8.11].

United Nations Educational, Scientific and Cultural Organisation (2005)

Education For All global monitoring report 2006: literacy for life. Geneva:

UNESCO. URL: http://unesdoc.unesco.org/images/0014/001416/141639e.pdf [accessed 08.8.11].

Williams, E. (1998) Investigating bilingual literacy: evidence from Malawi and Zambia. London: Department for International Development. (Serial No: 24). URL: http://www.dfid.gov.uk/r4d/PDF/Outputs/Misc Education/paper24.pdf [accessed 08.8.11].

World Economic Forum (2009) The global information and technology report 2008-2009. World Economic Forum. URL:

http://www.insead.edu/v1/gitr/wef/main/fullreport/index.html [accessed 12.9.09).

\section{The Occasion}

This paper presents the findings of an MSc dissertation, entitled Library Aid to Developing Countries: A case study investigating how a Western literary library model is integrated into a Sub-Saharan African oral culture within the Malawian primary education system, which won the LIRG Student Research Prize 2010.

\section{Acknowledgement}

The dissertation on which this research paper is based was submitted to the University of the West of England, Bristol in accordance with the requirements of the degree of MSc in Information \& Library Management, 2010.

A previous version of this paper was published in Aslib Proceedings:

Anderson, J. And Matthews, P. (2010) A Malawian school library: culture, literacy and reader development, Aslib Proceedings: New Information Perspectives, 62(6), 570-584. 


\section{Open access and copyright}

Library and Information Research is an open access journal. A freely available copy of this paper may be downloaded from the journal's website: http://www.cilipjournals.org.uk/lir

Copyright and associated moral rights in works published in Library and Information Research are retained by the author(s) but this paper may be used freely, with proper attribution, in educational and other non-commercial settings. 